\title{
Impact of mismatch repair (MMR) genetic test result on perceived cancer risk and cancer screening
}

\author{
Monica Dandapani, Margery Rosenblatt, Anu Chittenden, Rowena Mercado, Judy E Garber, Sapna Syngal, \\ Elena M Stoffel
}

From 13th Annual Meeting of the Collaborative Group of the Americas on Inherited Colorectal Cancer Honolulu, Hawaii, USA. 16-17 October 2009

\section{Background}

Information recall after genetic testing has been examined extensively in patients at risk for Hereditary Breast Ovarian Cancer. We examined perceived cancer risk, screening practices, and genetic testing-specific distress in individuals undergoing genetic testing for Lynch syndrome.

\section{Methods}

Individuals who underwent clinical genetic testing for Lynch syndrome at Dana Farber Cancer Institute were enrolled in a longitudinal questionnaire study eliciting information on perceived cancer risk, cancer worry, cancer screening and health behaviors prior to testing and after a clinical visit at which genetic test results were disclosed. Level of genetic test specific distress was assessed using the Multidimensional Impact of Cancer Risk Assessment Questionnaire (MICRA), and comparisons between groups were made using Kruskal Wallace non parametric analyses.

\section{Results}

129 subjects (average age 47 years) completed questionnaires, $68 \%$ were female and $53 \%$ had a personal history of cancer. Genetic test results were classified as: Positive for pathogenic MMR mutation $(n=23$, $18 \%)$, True Negative for familial MMR mutation $(\mathrm{n}=17,13 \%)$, Indeterminate negative (no previously identified family mutation) $(\mathrm{n}=79,61 \%)$, and Variant of uncertain significance (VUS) $(n=10,8 \%) .116 / 129$ $(90 \%)$ of participants correctly recalled their genetic

\footnotetext{
* Correspondence: monica_dandapani@dfcl.harvard.edu Dana-Farber Cancer Institute, Boston Massachusets 02115, USA
}

test result. When asked to estimate their cancer risk compared to other people their same age, 22/23 (96\%) of individuals with a positive genetic test result correctly indicated that they were at higher risk, and 14/ $17(82 \%)$ individuals with a true negative result indicated that their risk was the same as other people their age. However, 36/79 (46\%) of those with indeterminate negative results incorrectly reported their cancer risk was now the same or lower compared with others their age. $111 / 129(86 \%)$ of participants indicated that they worried about cancer the same or less than before they knew their genetic test result. Median genetic test-specific distress scores for individuals who received positive or VUS test results were significantly higher compared with indeterminate negative and true negative results $(\mathrm{p}<0.001)$.

All individuals with a positive genetic test result reported that they planned to have colorectal cancer surveillance once a year or more frequently. Interestingly, $61 / 79(77 \%)$ of individuals with indeterminate negative results and 7/17 (41\%) of those with true negative tests still planned to undergo colonoscopy screening every 2 years or more frequently.

\section{Conclusions}

Overall, participants accurately recalled the result of their genetic test for MMR mutations. Although some individuals with indeterminate negative results may misinterpret their test result as meaning that their cancer risk is "lower," most plan to continue frequent colorectal cancer surveillance. While only $8 \%$ of our cohort received a VUS result, our findings suggest that these patients may experience genetic test-specific distress comparable to that of individuals who receive a positive 
genetic test result. Our results suggest that post test counseling is necessary to reinforce clinical implications of genetic test results and recommendations for cancer screening.

Published: 25 May 2010

doi:10.1186/1897-4287-8-S1-P6

Cite this article as: Dandapani et al:: Impact of mismatch repair (MMR)

genetic test result on perceived cancer risk and cancer screening.

Hereditary Cancer in Clinical Practice 2010 8(Suppl 1):P6.

Submit your next manuscript to BioMed Central and take full advantage of:

- Convenient online submission

- Thorough peer review

- No space constraints or color figure charges

- Immediate publication on acceptance

- Inclusion in PubMed, CAS, Scopus and Google Scholar

- Research which is freely available for redistribution

Submit your manuscript at www.biomedcentral.com/submit 